\title{
Resource partitioning by species but not sex in sympatric boobies in the central Pacific Ocean
}

\author{
Hillary S. Young ${ }^{1, *}$, Scott A. Shaffer ${ }^{2,5}$, Douglas J. McCauley ${ }^{1}$, Dave G. Foley ${ }^{3,4}$, \\ Rodolfo Dirzo' ${ }^{1}$, Barbara A. Block ${ }^{1}$ \\ ${ }^{1}$ Department of Biology, Stanford University, 371 Serra Mall, Stanford, California 94305, USA \\ ${ }^{2}$ Ecology \& Evolutionary Biology, University of California Santa Cruz, Santa Cruz 95060, USA \\ ${ }^{3}$ Joint Institute for Marine and Atmospheric Research, University of Hawaii, Honolulu, Hawaii 96822, USA \\ ${ }^{4}$ NOAA/NMFS/SWFSC/Environmental Research Division, 1352 Lighthouse Avenue, Pacific Grove, California 93950-2097, USA
}

${ }^{5}$ Present address: Department of Biological Sciences, San José State University, San José, California 95192, USA

\begin{abstract}
Sympatric species with similar ecological requirements and differences in body size would be expected to partition resources to facilitate coexistence. For sexually dimorphic species, we may expect resource partitioning by gender as well as by species identity. However, it is difficult to document species and sexual resource partitioning in marine ecosystems, given the intractability of these systems and the vagility of many marine animals. Here, we examined differences in the foraging behavior and prey selection of 2 congeneric and coexisting seabird species - masked boobies Sula dactylatra and red-footed boobies Sula sula - on Palmyra Atoll in the equatorial Pacific Ocean. These seabirds exhibit substantial size dimorphism between species and also have reverse sexual dimorphism within species. Pronounced interspecific differences in foraging patterns were observed with high-resolution GPS tracking devices, where smaller red-footed boobies conducted longer foraging trips (in both time and distance). Red-footed boobies also had more frequent landings on the sea surface, slower mean and maximum travel speeds, and more westerly trip azimuths. Stable isotope and diet analyses produced data that complemented returns from electronic tagging. Stable isotope ratios of carbon indicated that masked boobies foraged on prey with a less pelagic $\delta^{13} \mathrm{C}$ signature compared to red-footed boobies. In contrast, no gender differences were identified in any foraging parameters. The mechanisms for maintenance of these pronounced differences in niche partitioning across species were not explicitly examined, yet the data suggest physiological variation across species may be a more plausible mechanism than competitive interactions.
\end{abstract}

KEY WORDS: Resource partitioning · Reverse sexual dimorphism · Foraging ecology · GPS tracking · Sula sula $\cdot$ S. dactylatra

\section{INTRODUCTION}

Resource partitioning, whether by habitat or diet, is one of the principle factors that permits multiple species to cohabit the same environment (Pianka 1981, Martin 1996, McKane et al. 2002). Partitioning of resources also occurs between sexes of the same species (Selander 1966, Andersson \& Norberg 1981, Belk et al. 1988). In many cases, body size plays a role in facilitating the partitioning that occurs within a species, as well as across species. In order to meaningfully exam- ine patterns of intra- and interspecific resource partitioning, it is necessary to collect high-resolution information on the patterns of space and resource use of subject taxa.

Previous studies of space and resource use in seabirds indicate that sympatric species partition resources temporally (Croxall \& Prince 1980, Harrison 1990), spatially (Weimerskirch et al. 1986, Anderson \& Ricklefs 1987, Mori \& Boyd 2004), and by type of prey (González-Solís et al. 2000a, Catry et al. 2009). In tropical oceanic environments dominated by oligotrophic conditions, larger 
species, which have higher flight costs but greater competitive ability, often dominate the areas where productivity and prey are somewhat elevated (e.g. upwelling zones) (Ballance et al. 1997, Jaquemet et al. 2005). Sexually dimorphic seabird species tend also to significantly partition resources between sexes, with the larger sex generally foraging closer to the colony and taking larger prey (Selander 1966, Gilardi 1992, González-Solís et al. 2000a, Spear et al. 2007). The origin of these inter- and intraspecific patterns of partitioning may occur as a direct result of differentiation evolved to maximize forage yields, or as an indirect outcome of the influence of morphologies selected upon for other reasons that affect flight performance, habitat selection, and diet (Ballance et al. 1997, Shaffer et al. 2001, Lewis et al. 2002).

Tropical seabirds face unique foraging challenges because productivity in tropical marine ecosystems typically is low, prey are patchily distributed, and thermal stresses are high (Ashmole 1971, Longhurst \& Pauly 1987). These factors presumably expose tropical seabirds to intense selection for improving foraging efficiency (Ainley 1977, Au \& Pitman 1986, Weimerskirch et al. 2008) and may thus exert strong selection pressure for the maintenance of body size differences in tropical seabird species (Lewis et al. 2002, Weimerskirch et al. 2005, 2006). These tropical conditions provide an appropriate setting in which to investigate patterns of niche differentiation in marine ecosystems.

Two of the most common species of tropical boobies (Sulidae) in the central Pacific are the masked Sula dactylatra and the red-footed booby Sula sula. Ranges of these species overlap, and they often cohabitate the same breeding colonies. These 2 booby species differ significantly in size where masked boobies weigh nearly twice that of red-footed boobies (present study). Both species also exhibit reversed sexual dimorphism, where masked booby (MB) females are from 8 to $27 \%$ heavier than males, and red-footed booby (RF) females are approximately $15 \%$ heavier than males (Fairbairn \& Shine 1993, Lormée et al. 2005). Both species have been shown to exhibit spatial resource partitioning by sex, with females foraging further and for longer periods away from the colony (Weimerskirch et al. 2005, 2006, 2009a,b). The birds also likely have different flight costs (based on wing loading calculations and measured costs of flight), with RFs having substantially lower flight costs than MBs (Ballance et al. 1997, Brewer \& Hertel 2007). Colony surveys show that both species have similar nest-attendance patterns (Anderson \& Ricklefs 1992, Lormée et al. 2005), and at-sea surveys suggest similarity in foraging behavior and co-occurrence in mixed species flocks (Ballance et al. 1997, Spear et al. 2007). No studies have compared foraging behavior of these bird species in the same location.
The present study used GPS tracking tag technology, diet analyses, and stable isotopes to examine the hypotheses that the 2 boobies in this low-productivity system would demonstrate clear niche partitioning both between species and by sex within species. GPS tags were affixed to breeding seabirds and provided high-resolution location fixes of foraging behavior. Analyzing stable isotope ratios of $\mathrm{C}$ and $\mathrm{N}$ can provide information on space use and trophic position (respectively), a method which has been used extensively to determine seabird movements and dietary patterns (Inger \& Bearhop 2008, Phillips et al. 2009). Values of $\delta^{13} \mathrm{C}$ tend to be more depleted in pelagic waters relative to coastal reef communities, allowing us to track how offshore seabirds are moving to obtain resources, and $\delta^{15} \mathrm{~N}$ undergoes trophic enrichment, providing a useful proxy for determining an organism's trophic position (Michener \& Kaufman 2007). At-sea locations were also compared to remotely sensed oceanographic data to investigate the relationships between foraging behavior and the environment.

This project represented a first effort to collect data on niche differentiation in masked and red-footed boobies resident at the same colony. The current analysis provides a valuable point of reference for which to compare the foraging patterns of masked and red footed boobies in the Pacific, to populations elsewhere in the tropics.

\section{MATERIALS AND METHODS}

This research was conducted on Palmyra Atoll, $\left(5^{\circ} 52^{\prime} \mathrm{N}, 162^{\circ} 04^{\prime} \mathrm{W}\right)$ in the central Pacific Ocean over a 2 yr period between the periods from 25 May to 15 October 2007 and 15 September to 27 November 2008. Palmyra consists of a ring of coral-derived islets that encircle a central saltwater lagoon system. The islets of Palmyra are generally forested, with occasional grassland areas and bare rock patches that serve as nesting area for colonies of ground nesting Sula dactylatra (MBs). Sula sula (RFs) nest almost exclusively in trees and shrubs. Both species nest year round, with no apparent synchrony across species in nesting cycles. Nest counts range from 1000 to 2500 pairs for RFs and only 10 to 50 pairs for MBs (Fefer 1987, E. Flint unpubl. data, H. S. Young unpubl. data).

To study their movement patterns, boobies were captured from a variety of locations around the atoll at either dawn or dusk while they were on their nests. All birds in the present study were either incubating eggs or brooding young chicks. On first capture, birds were fitted with a $30 \mathrm{~g}$ GPS data logger (Technosmart, GiPSy-2) engineered to record GPS positions $( \pm 10 \mathrm{~m}$ accuracy) approximately every $10 \mathrm{~s}$, taped to 3 central 
tail feathers. Loggers were left on birds for 24 to $48 \mathrm{~h}$. RFs were tracked in both 2007 and 2008, while MBs were only tracked in 2008. In total, we had 54 tracks from RFs (22 male, 28 female, 4 unsexed; 20 chick nests and 34 egg nests) and 34 tracks from MBs (18 male and 16 female; 25 chick nests and 9 egg nests). Upon second capture, we removed loggers, applied steel identification bands, measured mass with spring balance $( \pm 5 \mathrm{~g})$, and measured culmen, tarsus, and head-bill lengths with calipers $( \pm 1 \mathrm{~mm})$. We also collected blood from a brachial vessel and from 2 to 4 feather samples (underwing covert) from each bird for genetic (blood) and stable isotope analyses (blood and feather). Food samples spontaneously regurgitated during tagging efforts were collected. Feather samples were also obtained from chicks in nearby RF nests (to avoid additional stress to nests of tagged birds). Nest state (with egg[s] or chick) was recorded for every bird studied. Boobies were sexed by vocalization, coloration of fleshy areas near bills, and by body size (determined from measurements); sex identification of all RFs was also confirmed via molecular analysis (not necessary for MBs given more substantial variation in field identification features).

All locations from GPS data sets were filtered using a backward-forward iterative speed filter (McConnell et al. 1992) based on a maximum travel speed of $90 \mathrm{~km} \mathrm{~h}^{-1}$. Given that tags were based on GPS technology, $<0.5 \%$ of location data were removed. Occasionally, data loggers lost satellite acquisition for periods exceeding $10 \mathrm{~min}$, or batteries lost charge before the bird returned. In such cases $(\mathrm{n}=31)$, tracks were examined individually; only complete portions of tracks were utilized for analysis, and data on area restricted search (ARS) behavior and total distance travelled were not taken from incomplete tracks.

Boobies plunge dive for prey to depths of up to $2.4 \mathrm{~m}$ for an average of $1.8 \mathrm{~s}$ (Weimerskirch et al. 2005). Therefore, it was possible to infer foraging activity and/or periods when birds landed on the sea surface by identifying all locations when travel speeds were $<5 \mathrm{~km} \mathrm{~h}^{-1}$ between successive sampling intervals (locations within $1 \mathrm{~km}$ of land were excluded in this analysis) (Weimerskirch et al. 2008). Frequency of landings was determined by the number of landings per hour over an entire trip. Mean and maximum flight speeds were calculated based on travel speeds $>5 \mathrm{~km} \mathrm{~h}^{-1}$. Trip length was calculated both as distance travelled from nest $(\mathrm{km})$ and as duration of travel (h) between departure and return to nest. ARS behavior (size of ARS and number per trip) was determined by the fractal landscape method (Tremblay et al. 2007). The outbound and inbound azimuths were determined by establishing the angular difference between the nest and the location of the bird when it was $4 \mathrm{~km}$ from the atoll. The maximum azimuth was the angular difference between the nest and the location of the bird at its maximum range from the colony. All analyses were conducted using custom algorithms created in MatLab 2008b (The Mathworks).

Daily ocean surface vector winds from the Seawinds sensor carried aboard NASA's Quikscat spacecraft (e.g. Naderi et al. 1991, Perry 2001) were extracted for an area chosen to encompass the spatial range of the boobies. The wind directions were then averaged for the region and compared with the outbound azimuth provided by the GPS tags. Comparisons were performed using the ANOVA function of the Matlab Statistics toolbox. Average daily chlorophyll a concentrations for each flight were obtained from the moderate imaging spectrometer (MODIS) carried aboard NASA's Aqua spacecraft (O'Reilly et al. 2000). Average daily sea-surface temperatures (SST) were derived from the blended microwave/infrared product produced by Remote Sensing Systems Inc. of Santa Rosa, California (Gentemann et al. 2009).

Laboratory analysis. For isotopic analysis, feather samples were rinsed in deionized water, dried at $60^{\circ} \mathrm{C}$, and finely chopped. Blood samples were stored frozen, freeze dried, and powdered. Samples were run at the Stanford Stable Isotope Biogeochemistry Laboratory (SIBL; Thermo Finnegan Delta-Plus XP IRMS), which has an analytical error of $\pm 0.2 \%$ for both $\mathrm{C}$ and $\mathrm{N}$.

The sex of RF individuals was confirmed for a subset of individuals ( $\mathrm{n}=24$ ) from blood using 2 different molecular methods, each targeting homologous fragments on the $\mathrm{Z}$ and $\mathrm{W}$ chromosome. One polymerase chain reaction (PCR) used the primers 2550F and 2718R (Fridolfsson \& Ellegren 1999), and resulting fragments were run out on $2 \%$ agarose gels. A separate PCR made use of primers M2 (Bantock et al. 2008) and P8 (Griffiths et al. 1998). The latter primer was fluorescently labeled, enabling fragment analysis on an automated ABI 3130xl sequencer (Applied Biosystems). The 2 methods yielded identical results and matched with field identification of sex.

For analysis of regurgitated samples, we measured the length of each food item that was sufficiently intact (fish: fork length; squid: mantle length). Since fish were in various states of digestion, we used published length-to-weight conversion factors to estimate their mass (Le Corre et al. 2003). Muscle tissue from the most intact flying fish (Exocetidae, $\mathrm{n}=25$ ) and squid (Ommastrephidae, $\mathrm{n}=12$ ) individuals was freezedried for isotopic analysis, but was not lipid extracted ( $\mathrm{C}: \mathrm{N}$ ratio was always $<3.3$, indicating low lipid levels). Stomach contents were obtained from $34 \mathrm{RFs}$ and 14 MBs (each bird was only sampled once), yielding a total of 91 individual prey items in sufficiently good condition for analysis. 
Statistical analyses. We first tested for differences in body size across species and sex within species. Morphological data collected from birds could not be normalized and was thus analyzed using Wilcoxon tests, with sequential Bonferroni corrections. To integrate multiple metrics of body size, the 3 linear measurements (culmen, head-bill, and tarsus) and body mass were analyzed via principal components analysis.

To analyze foraging data, we used mixed-effects ANOVAs to determine if foraging patterns (i.e. distance travelled, trip duration, maximum distance) differed between species and sex (independent fixed factors), with bird number (i.e. individual bird) as a random factor. To analyze effects of species and sex on $\delta^{13} \mathrm{C}, \delta^{15} \mathrm{~N}$, prey size, and prey composition by diet sample we used fixed-effect ANOVAs (as there was only 1 sample per bird). Prior to each of these analyses, data were analyzed for normality using the Shapiro-Wilk test, and non-normal data were Box-Cox transformed. Within species, we also tested major foraging parameters for differences by nest status and by year (for RFs only). Since no significant differences were found for comparisons involving nest status or year tracked, we did not include these covariates in our final analyses.

All graphs/tables depict untransformed data. All mean $( \pm 1 \mathrm{SD})$ values are shown untransformed. Statistical analyses on body size, foraging parameters, isotopic analysis, and diet were performed in JMP 7 (SAS Institute).

\section{RESULTS}

\section{Body size}

There were significant body size differences both between species and between sexes within species (Table 1). Average weights of Sula dactylatra were 2 times greater than those of $S$. sula (mean of 1779 and $893 \mathrm{~g}$, respectively), and there was no overlap in body mass between species. In comparison, the differences in body mass between the sexes (within a species) were smaller, but significant (females were $12 \%$ larger than males for MB and $13 \%$ for RF), with some overlap between sexes.

Results from principal components analysis on body size showed that the first principal component (PC1) explained $95 \%$ of the variance; thus, we used these PC1 values as an index of overall bird size. The differences observed in PC1 between species and sex were similar to those observed using a simple mass metric, although they show less interspecific variation $(48 \%$ difference between species) and greater gender variation within a species $(29 \%$ difference between sexes for $\mathrm{MB}$, and $15 \%$, for $\mathrm{RF}$ ).

\section{Foraging distance and timing}

GPS tracking revealed that RFs travelled more than twice as far as MBs per foraging trip, both in terms of total distance travelled and maximum range from the colony (Fig. 1A, Table 2). Mean trip duration was approximately 3 times longer for RFs than for MBs (means of 8.67 and $2.84 \mathrm{~h}$, respectively). The frequency of trip duration, maximum range, and distance flown for MBs were normally distributed compared to values for RFs (Fig. 2). In contrast to MBs, RFs appeared to have 2 distinct peaks in trip length and duration, with a break between long trips and shorter trips at approximately $35 \mathrm{~km}$ in distance and $5 \mathrm{~h}$ in duration (Fig. 1B,C).

Trip timing also varied by species: MBs left later in the morning (mean of 10:40 local departure for MBs and 08:28 for RFs) and returned earlier in the evening (mean of 13:41 return for MBs and 16:41 for RFs; Table 2, Fig. 2C). For RFs only, trip distance and maximum range were positively linearly related with return time to the colony (trip distance $\mathrm{R}^{2}=0.59, \mathrm{p}<0.0001$, max range $\mathrm{R}^{2}=0.67, \mathrm{p}<0.0001$ ). Starting time for $\mathrm{RFs}$ was also correlated with average travel speed $\left(\mathrm{R}^{2}=\right.$ $0.29, \mathrm{p}=0.0006)$ and maximum travel speed $\left(\mathrm{R}^{2}=0.23\right.$, $\mathrm{p}=0.0001)$.

Table 1. Sula dactylatra and S. sula. Morphological comparisons of masked and red-footed boobies by sex. Statistics are results of Wilcoxon tests of sex within species. PC1 values are the first principal component scores of the analysis on all other size metrics. Significant results are indicated in bold.Values are presented as means $\pm \mathrm{SD}$

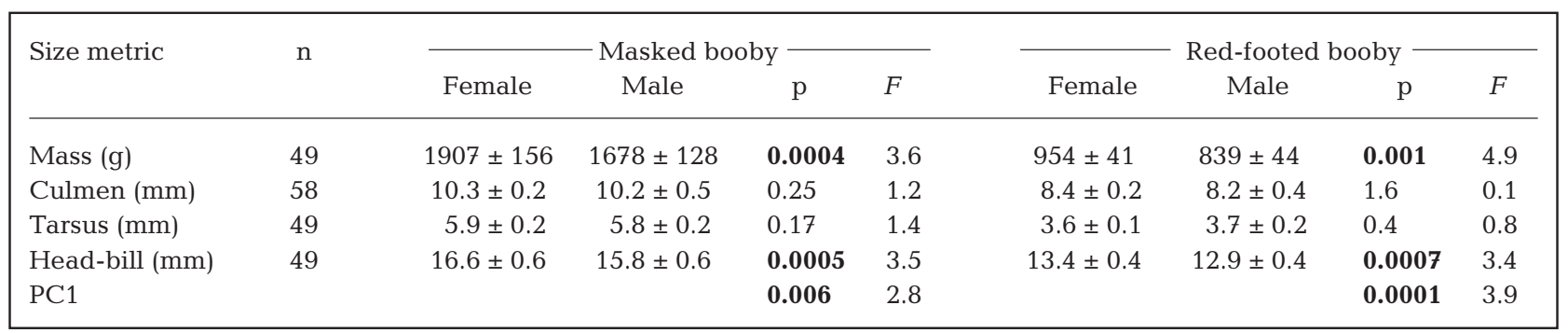




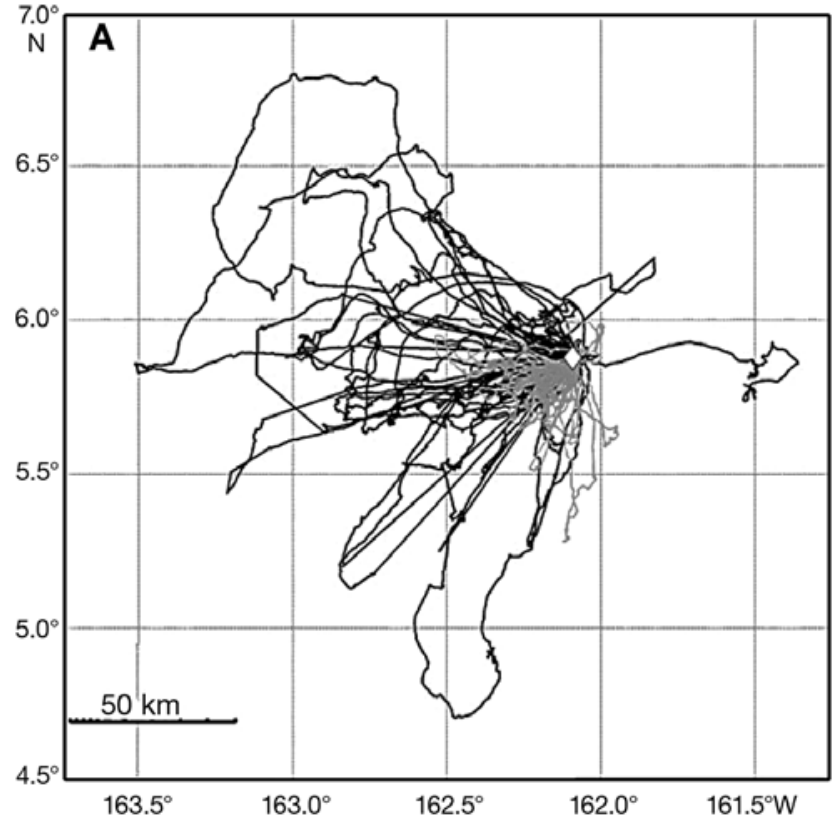

Fig. 1. Sula dactylatra and S. sula. (A) All tracks from masked (grey) and red-footed (black) boobies. (B) One typical long trip and one typical short trip from red-footed boobies. (C) Two typical trips by masked boobies. In Panels B and C landings are shown as grey circles
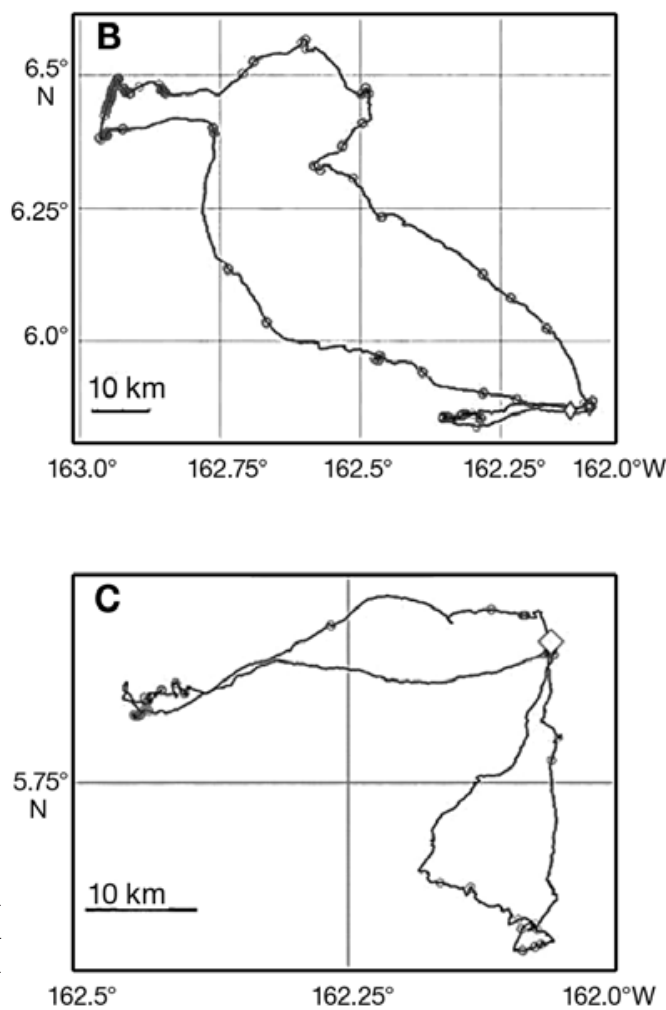

Table 2. Sula dactylatra and S. sula. Foraging parameters of masked (MB) and red-footed (RF) boobies. Values are presented as means \pm SD. Mixed-effects ANOVA models are used to compare whether attributes differ by species and sex (within species), with bird identity as a random factor. Significant results are indicated in bold. ARS: area restricted search zone

\begin{tabular}{|c|c|c|c|c|c|c|c|}
\hline & \multirow[t]{2}{*}{$\mathrm{n}$} & \multicolumn{2}{|c|}{- Mean \pm SD } & \multicolumn{2}{|c|}{ Species effect } & \multicolumn{2}{|c|}{ Sex effect } \\
\hline & & $\mathrm{MB}$ & $\mathrm{RF}$ & $\mathrm{p}$ & $F$ & $\mathrm{p}$ & $F$ \\
\hline Trip duration (h) & 61 & $2.84 \pm 1.52$ & $8.67 \pm 5.30$ & 0.0001 & 33 & 0.52 & 0.7 \\
\hline Total distance travelled (km) & 57 & $89.41 \pm 38.39$ & $195.59 \pm 125.44$ & 0.003 & 10 & 0.85 & 0.2 \\
\hline Maximum foraging range $(\mathrm{km})$ & 61 & $29.35 \pm 11.50$ & $67.52 \pm 44.17$ & 0.0001 & 19 & 0.96 & 0.03 \\
\hline Azimuth at max. range & 60 & $229.99 \pm 8.42$ & $241.17 \pm 11.01$ & 0.004 & 9.1 & 0.59 & 0.7 \\
\hline Outbound azimuth & 80 & $213.56 \pm 41.98$ & $241.61 \pm 70.12$ & 0.003 & 9.6 & 0.22 & 1.5 \\
\hline Inbound azimuth & 55 & $222.63 \pm 48.99$ & $214.39 \pm 99.59$ & 0.67 & 0.2 & 0.66 & 0.4 \\
\hline Travel rate $\left(\mathrm{km} \mathrm{h}^{-1}\right)$ & 82 & $43.17 \pm 3.68$ & $36.37 \pm 7.58$ & 0.05 & 3.9 & 0.87 & 0.1 \\
\hline Max travel rate $\left(\mathrm{km} \mathrm{h}^{-1}\right)$ & 88 & $84.12 \pm 3.82$ & $73.82 \pm 13.57$ & 0.001 & 18.1 & 0.94 & 0.1 \\
\hline Time to first landing (min) & 74 & $23.36 \pm 14.73$ & $48.40 \pm 93.86$ & 0.02 & 6.2 & 0.76 & 0.3 \\
\hline Time to last landing (min) & 54 & $11.71 \pm 14.72$ & $94.42 \pm 140.06$ & 0.001 & 23.7 & 0.84 & 0.2 \\
\hline Mean start time (time of day) & 54 & $10: 40 \pm 2: 09$ & $8: 28 \pm 2: 79$ & 0.001 & 18.7 & 0.18 & 0.8 \\
\hline Mean end time (time of day) & 72 & $13: 41 \pm 2: 46$ & $16: 41 \pm 4: 84$ & 0.007 & 8.1 & 0.59 & 0.6 \\
\hline Landings $\mathrm{h}^{-1}$ & 71 & $15.41 \pm 10.31$ & $28.12 \pm 34.84$ & 0.04 & 4.5 & 0.02 & 4.0 \\
\hline Number of ARS (trip ${ }^{-1}$ ) & 30 & $4.06 \pm 2.38$ & $5.75 \pm 2.67$ & 0.56 & 2.3 & 0.87 & 1.2 \\
\hline Number of ARS $\left(\mathrm{h}^{-1}\right)$ & 28 & $1.42 \pm 0.59$ & $0.95 \pm 0.29$ & 0.04 & 5.0 & 0.94 & 0.1 \\
\hline Size of ARS $(\mathrm{km})$ & 138 & $0.84 \pm 0.54$ & $0.69 \pm 0.65$ & 0.16 & 2.0 & 0.14 & 1.9 \\
\hline
\end{tabular}

\section{Flight speed and activity patterns}

MBs had higher mean and maximum flight speeds, by approximately $15 \%$, than those of RFs (Table 2). MBs also had shorter distances and times from last landing (or plunge) while enroute to the colony com- pared to RFs. There were no significant differences by sex or species in frequency of landings, distance to first landing, or mean distance to landing.

There were no significant differences in the size of ARS zones (Table 2) by either species or sex. Likewise, there was no difference in the absolute number of ARS 

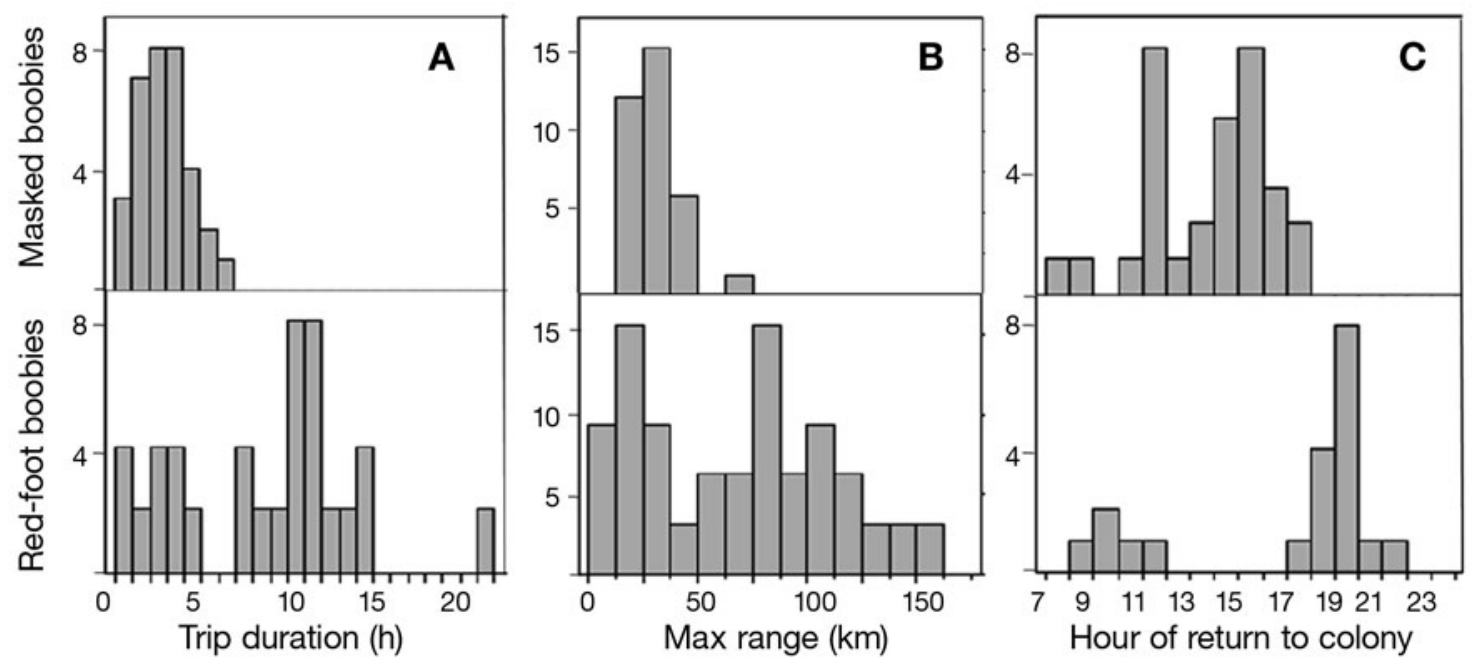

Fig. 2. Sula dactylatra and S. sula. Histograms of number of trips by (A) trip duration, (B) maximum range, and (C) return time, for masked and red-footed boobies showing 2 distinct peaks in distribution of trips for red-footed boobies and only 1 peak in trip distribution for masked boobies

periods per trip. However, because RF trips were so much longer in duration than MB trips, the frequency of ARS activity was significantly higher for MBs than for RFs.

\section{Foraging habitat and environmental factors}

Both bird species flew primarily in a western direction from the atoll. However, MBs had slightly more southerly outbound and maximum azimuths (Fig. 3: rose plots). There were no differences between species for inbound azimuths (Table 2). There were no significant differences in any measurements of trip azimuth by sex within species either.

SST during foraging trips ranged from 25.5 to $29.0^{\circ} \mathrm{C}$; annual average SST was slightly higher to the west of the atoll. Primary productivity in the region was low; chlorophyll a ranged from 0.1 to $0.2 \mathrm{mg} \mathrm{m}^{-3}$ and was slightly higher to the south than to the north of the atoll,
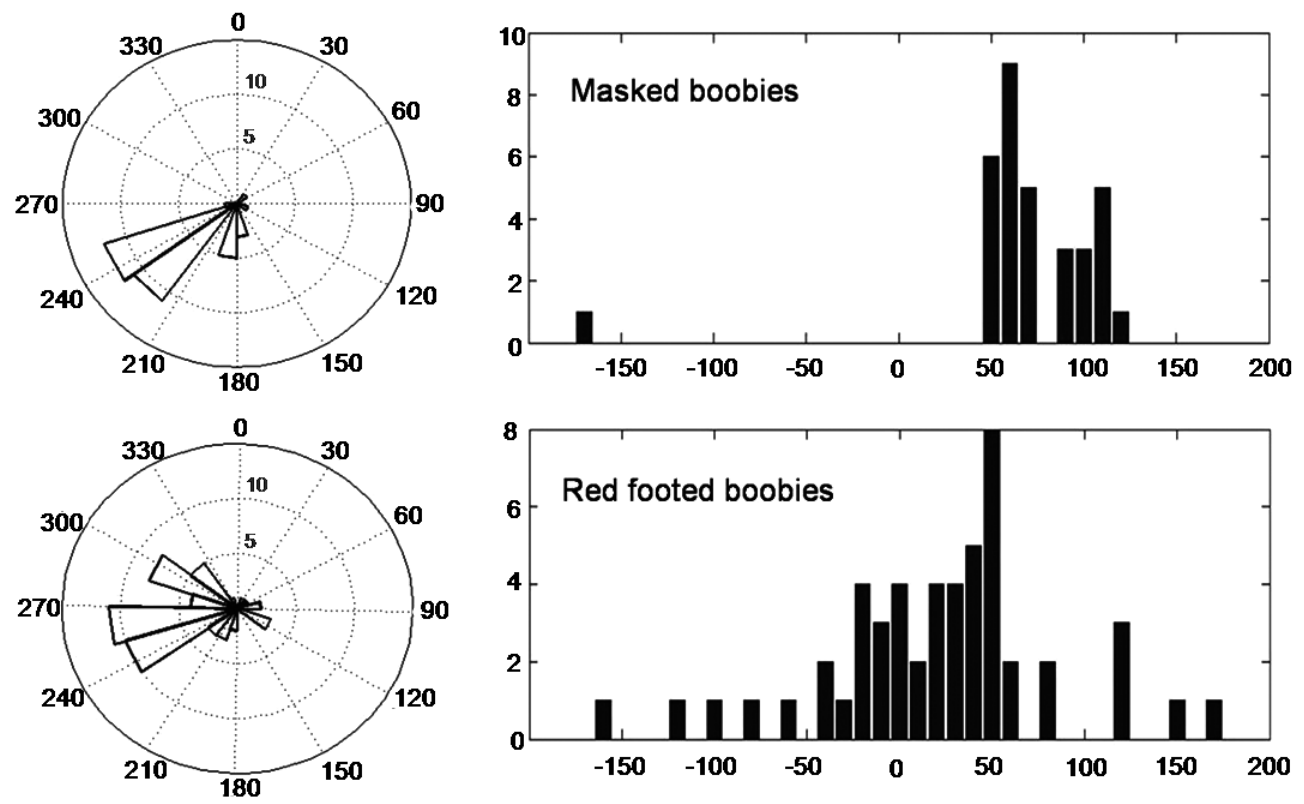

Fig. 3. Sula dactylatra and S. sula. Left panels depict rose plots of all outbound trip azimuths for masked (top) and red-footed (bottom) boobies. Right panels are histograms of the differences between wind direction and outbound azimuth for each trip for both species. Red-footed boobies head more directly west and keep the wind more directly behind their rear-quarters on outbound trips as compared to masked boobies 
with hotspots directly north of the Palmyra Atoll and neighboring Kingman Atoll. However, all variations in SST and chlorophyll a over the period of the present study were small in the region delimited by maximum flight ranges of all birds, and the resolution of data available was too coarse given the small travel distances of these birds. Thus, no attempt was made to analyze differences among genders and species by these 2 variables.

Analysis of wind patterns in the region showed wind direction to be quite variable over the course of the year, oscillating in an annual cycle from northeasterly to southeasterly as the Intertropical Convergence Zone moved northward and southward over the atoll. For all trips, the wind strength was always $>10$ knots; maximum wind speed during a single trip was 15 knots. The difference between outbound azimuth and average wind direction for each trip was significantly different between species $(F=14, \mathrm{p}<0.001)$, but not between sexes within species.

\section{Prey type}

The diet of both species was numerically dominated by flying fish (predominantly Exocoetidae), composing $94 \%$ of diet samples for MBs and $70 \%$ of diet samples for RFs. The remainder of the diet was composed of squid (predominantly Ommastrephidae). By biomass, flying fish appeared to comprise an even more significant component of the diet; approximately $99 \%$ of the diet by mass for MBs and $92 \%$ for RFs. For samples composed of flying fish, the average prey size was significantly larger for MBs (means: $245 \pm 136 \mathrm{~g}$ and $26.6 \pm$ $6.4 \mathrm{~cm}$ ) compared to RFs (means: $134 \pm 91 \mathrm{~g}$ and $20.6 \pm$ $4.0 \mathrm{~cm}$ ) (length: $\mathrm{p}=0.01, t=3.3$; mass: $\mathrm{p}=0.01, t=2.8$ ). The size and weight of fish did not differ significantly between sexes within a species. There was an insufficient number of squid samples for MBs to compare size of squid by species or by sex within booby species.

\section{Isotopic differences}

Feather tissue for MBs ( $\mathrm{n}=16$ ) was slightly, but significantly more depleted in $\delta^{13} \mathrm{C}$ than values obtained from RFs ( $\mathrm{n}=55)(\mathrm{p}=0.001, t=3.50$; Fig. 4). Blood samples showed similar small but significant results; although the difference was very small, there was no overlap in $\delta^{13} \mathrm{C}$ values between species in blood samples (MB: $\mathrm{n}=9$; RF: $\mathrm{n}=11 ; \mathrm{p}=0.01, t=3.7$; Fig. 4). Feathers from RF chicks $(\mathrm{n}=10)$ were not significantly different in $\delta^{13} \mathrm{C}$ from adult RFs. There were no significant differences in mean $\delta^{15} \mathrm{~N}$ between species or age classes for either feathers or blood. There were no sig-

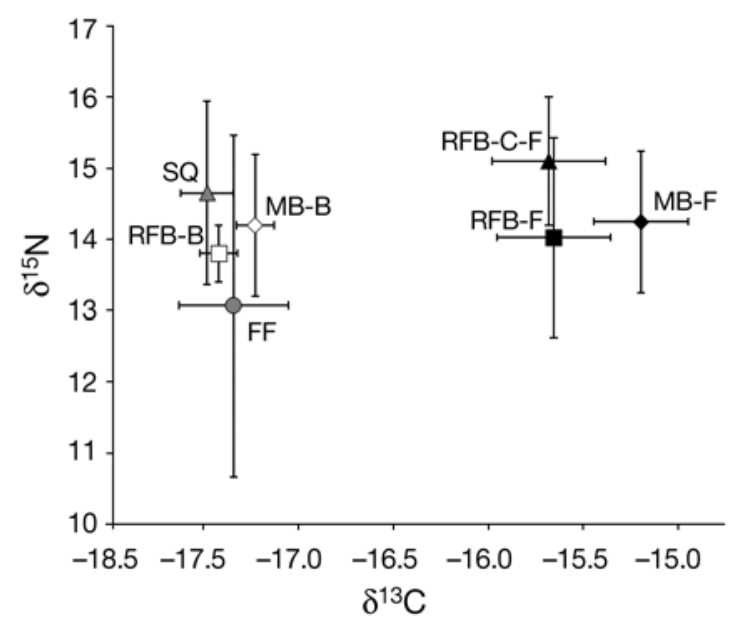

Fig. 4. Sula dactylatra (masked booby, MB) and $S$. sula (redfooted booby, RFB). Isotopic carbon and nitrogen values of feathers (-F, black symbols) and blood (-B, white symbols) of adult $S$. dactylatra, the masked booby (MB), and adults. Values are also shown for feathers of red-footed booby chicks (RFB-C), and for muscle (grey symbols) of the common prey items squid (SQ) and flying fish (FF). Error bars $=\mathrm{SD}$

nificant sex differences in isotopic values for either RFs or MBs. Values for both species were consistent with a diet composed largely of flying fish and squid.

\section{DISCUSSION}

In the present study, we demonstrated that booby species (Sula dactylatra, S. sula) nesting at Palmyra Atoll do partition resources by species - both in spatial and temporal domains and in prey type; however, they do not show evidence of sexual partitioning of resources. The large body size differences between the species and the documented effects of size on foraging patterns may explain the large species niche partitioning (González-Solís et al. 2000b, Shaffer et al. 2001). However, the observed magnitude of the distinction in habitat utilization at Palmyra between these 2 species was surprising, given that previous tracking work did not suggest widely disparate foraging patterns between these species at other locations (Weimerskirch et al. 2006, 2008).

One of the salient findings of our study is that we did not find support for resource partitioning between sexes within species. This result is in direct contrast to recent findings from a similar comparison of 2 sexually dimorphic sulid species in the Gulf of California, Mexico, where foraging differences were seen between sexes, but not between species (Weimerskirch et al. 2009a). However, in contrast to the oligotrophic waters around Palmyra Atoll, the study in Mexico took place 
in a higher productivity system, with nearby coastal upwelling, such that prey would be reliably available to these birds in closer proximity to their breeding colony. Thus, it is likely that birds have greater physiological capacity at the breeding colony in Mexico and, as a consequence, experience less pressure from interspecific competition in foraging compared to the tropical species we studied. Breeding in a higher productivity regime may also permit greater flexibility in parental roles when provisioning young compared to species that breed in a nutrient-poor tropical environment, which could manifest in intersexual differences observed in the former study (Weimerskirch et al. 2009a) and not the latter (the current study).

\section{Niche partitioning}

The 2 booby species used markedly different foraging strategies. The larger MBs took shorter trips both in distance and duration than did RFs. This contrasts with results from other GPS tracking studies, which suggested that MBs might forage further offshore than RFs. Incubating MBs at Clipperton Island $\left(10^{\circ} 18^{\prime} \mathrm{N}\right.$, $109^{\circ} 13^{\prime} \mathrm{W}$ ) frequently foraged an average of $144 \mathrm{~km}$ from the colony (and up to $250 \mathrm{~km}$ from the colony), while incubating RFs (at Europa Island, $22^{\circ} 22^{\prime} \mathrm{S}$, $40^{\circ} 21^{\prime}$ E) foraged an average of only $67 \mathrm{~km}$ from the colony (and up to $148 \mathrm{~km}$ from the colony) (Weimerskirch et al. 2005, 2008). However, our results are consistent with general opinion that RFs are more pelagic, based on earlier observations using conventional radio tracking, and with what would be predicted given the lower costs of flight of RFs (Anderson \& Ricklefs 1987). Thus, comparison of our results to other tracking studies of the same species suggests that there may be substantial differences in foraging patterns based on geographic location.

Further support of spatial separation between species comes from isotopic differences in $\delta^{13} \mathrm{C}$ in blood, which are consistent with patterns observed in tracking data; the more negative $\delta^{13} \mathrm{C}$ values of RFs suggest more pelagic feeding patterns (Fig. 4). Similar patterns, but greater variation in $\delta^{13} \mathrm{C}$ of feathers, suggest that these foraging differences between species remain during non-breeding periods and may even be amplified. That RF chick feathers are indistinguishable in $\delta^{13} \mathrm{C}$ from RF adult feathers, suggests that at least for this species at Palmyra there may not be large changes in foraging location between breeding and non-breeding periods. The small magnitude of changes observed in $\delta^{13} \mathrm{C}$ (in both feathers and blood) between species is likely due to small isotopic gradients typical of tropical waters (Cherel et al. 2008). Although differences in $\delta^{13} \mathrm{C}$ across genders have been observed in other studies of RFs, in which sexspecific foraging behavior was documented (Cherel et al. 2008), none were seen here.

We also observed distinct trip types and durations between species. Notably, RFs appeared to have 2 distinct trip modes, a less frequent 'short' trip, similar to the typical MB trip, and a more frequent 'long' trip. The alternation of long and short trips has been observed in a variety of other species, including wandering albatross Diomedea exulans (Weimerskirch et al. 1997), blue petrels Halobaena caerulea (Chaurand \& Weimerskirch 1994), and masked boobies at Clipperton (Weimerskirch et al. 2008). It seems that, at Palmyra, RFs, but not MBs, may exhibit this same pattern. However, further research is needed to document the mechanism driving this pattern and to understand why RFs, but not MBs, would exhibit trip alternations.

Consistent with their generally longer trips, RFs also departed earlier in the morning and returned later at night; many RFs did not return until well past dusk. While this is statistically true even if both short and long trips are pooled for RFs, the difference is most relevant for RFs on long trips (those $>35 \mathrm{~km}$ and $5 \mathrm{~h}$ in length). These birds left an average of $2.5 \mathrm{~h}$ earlier in the morning and returned $5.5 \mathrm{~h}$ later in the evening. These differences are probably largely driven by differences in trip length, possibly due to RFs targeting more distant foraging locations. The differences may also be facilitated by the comparatively larger eyes of RFs, which allow for greater crepuscular vision, although probably not for night foraging (Ashmole \& Ashmole 1967). This would then allow for temporal partitioning of resources, which may play a role in diet differences observed across species.

Higher flight speeds were also observed for MBs, as is consistent with studies showing MBs to have wing loading about 2-fold that of RFs (Hertel \& Ballance 1999). This higher wing loading likely explains the faster flight speeds of MBs, but it also likely increases the cost of flight (thus favoring faster, shorter trips for MBs).

Diet samples indicate that there is differentiation by species in the types of prey taken, with RFs taking smaller prey and consuming a greater proportion of squid. These interspecific differences in prey type and prey size are consistent with the differences that have been seen in other studies, although a greater proportion of squid by volume was identified for both species in other studies (Fefer et al. 1984, Asseid et al. 2006, Spear et al. 2007). Our sampling method (using only largely intact animals) may have disproportionately biased against squid and smaller prey, since they may be digested more quickly, potentially explaining the lower proportion of squid found in our study. However, the lower abundance of squid in MB diets compared to 
RF diet samples may also be partially explained by the earlier departure and later return of RFs, leading to higher activity in crepuscular hours when squid are more likely to be found (Roe 1974). The higher mass of individual fish prey items in MB diet samples may be related to the larger mass and higher wing loading of this booby species, allowing them to swallow and carry larger items. The lack of isotopic difference in $\delta^{15} \mathrm{~N}$ suggests that there were no significant differences in trophic position of prey consumed, as might be expected considering that both booby species feed on the same 2 prey types in an oligotrophic area. The high variability in $\delta^{15} \mathrm{~N}$ is likely due to the high variability in $\delta^{15} \mathrm{~N}$ seen in flying fish prey.

\section{Foraging context}

Both bird species foraged primarily in the western direction from the atoll. Multiple studies of seabirds in the tropics have used chlorophyll $a$ and/or SST levels to explain seabird use of specific areas in tropical oceans (Ballance et al. 1997, Jaquemet et al. 2005, Weimerskirch et al. 2005), and previous work suggests that RFs can adapt foraging patterns to forage in more productive waters (Weimerskirch et al. 2005). However, no major variation in SST or chlorophyll was observed at Palmyra that would explain this pattern. Given the strong easterly currents that surround Palmyra Atoll from the North Equatorial Counter Current, a high productivity eddy not detected by our course level metrics might exist to the west of the atoll (Hamman et al. 2004). It is possible that RFs take advantage of their more efficient flight abilities, to travel further to utilize more productive waters. However, this is not clearly supported by remotely sensed SST and chlorophyll data, and more detailed analysis of water productivity on a trip-by-trip basis would be needed to document any such patterns.

A more likely explanation for the westerly direction of both bird species is the prevailing wind direction. The westerly direction of outbound flight would allow them to fly with winds on their rear-quarters on outbound flights, which should be the most energyefficient means of travel, and with headwinds on the return flight (Pennycuick 1989). Other studies (Pennycuick 1989, Spear \& Ainley 1997) suggest that seabirds, and Pelicaniformes in particular, tend to fly with or across headwinds, in order to cover large distances and maximize prey detection. Flying the return leg into headwinds would be conducive to foraging, as birds would be able to maintain high flight speeds and low ground speeds, to facilitate searching. This is consistent with studies that show that RF increase landing frequency with time of day (Weimerskirch et al. 2005).
Wing loading should also be greater on the return leg, because birds would be returning with payloads of food. Greater wing loading on the return would allow boobies to penetrate headwinds more easily. The cause of significant differences observed in wind direction to flight direction between species is not immediately apparent. It may be that the differences in deflection from wind direction may be an artifact of the birds targeting different foraging zones, rather than a preference by the birds concerning wind direction. Another possible explanation for the identical return azimuth of both species is that it is a strategy to arrive in groups, as this has been documented to make them less vulnerable to kleptoparastism by frigatebirds, which are common at this site (Le Corre \& Jouventin 1997).

\section{CONCLUSIONS}

We used high resolution tracking data to examine hypotheses about habitat utilization in 2 species of boobies on Palmyra Atoll. A total of 565 h of high-resolution track data was obtained, and we identified clear species-specific foraging patterns, but no significant patterns of resource partitioning by gender.

It is unclear what maintains species-specific foraging patterns at Palmyra Atoll. Given the low abundance of MBs on the atoll, it seems intuitively unlikely that competitive exclusion of RFs by MBs could maintain these foraging differences. Given the much greater size of MBs it also seems doubtful that the reverse could occur. No aggressive behavior has been observed by the authors between these species at sea, and they nest in extremely close proximity to one another. It seems more likely that much of the differentiation in foraging patterns and resource use (i.e. lower flight speeds, smaller prey size, and later return times for RFs) is caused by physiological variation that evolved over time, which allows the species to partition resources (e.g. mass-related lower wing loading and larger eyes for RFs). There may also be interactions between physiological constraints of the birds (e.g. the size of prey they can carry and the times of day they can forage) and unidentified environmental factors, such as the location of different prey types, which drive these foraging differences. There is little published information on the distribution of the primary prey species of these birds, and no clear reason to predict there would be variation in prey abundance between foraging zones utilized by these 2 species.

If anatomical differences lead to high niche partitioning between species, then intraspecific competition may be more important than interspecific competition in affecting foraging behavior of a given species. This could explain why MB foraging patterns are so 
different at Palmyra compared to observations from Clipperton Island (Weimerskirch et al. 2008). The masked booby colonies at Clipperton are extremely large, and the birds may thus be forced to forage further off shore due to intraspecific competition (Lewis et al. 2001). The small colony size and thus low intraspecific competition at Palmyra may allow them to feed closer to the colony. Since RF colonies are large at Palmyra, there would still be strong intraspecific competition in that species.

The lack of support found in the present study for significant partitioning of resources by gender is also notable given the abundance of studies that have demonstrated resource partitioning across a wide variety of sexually dimorphic species, including these and other sulid species (Selander 1966, Gilardi 1992, González-Solís et al. 2000a, Weimerskirch et al. 2009a,b). Yet, some studies have found resource partitioning by sex in monomorphic species (Gray \& Hamer 2001, Peck \& Congdon 2006), and Weimerskirch et al. (2009a) found partitioning by sex, but not by species, despite the fact that species size differences were greater than sexual size differences. All of these results suggest that factors beyond size may be important in determining sexual partitioning and that sexual partitioning appears to be flexible within species and may be correlated to a variety of complex and local factors. Comparative studies across sites would help to elucidate the variables that lead to the occurrence or absence of resource partitioning by sex.

Acknowledgements. We thank the National Science Foundation, the National Geographic Society, the Tagging of Pacific Pelagics (TOPP) Program, and the Stanford Gabilan Graduate Fellowship, and Stanford at Sea for their financial support. For logistical and material support we thank the US Fish and Wildlife Service (Palmyra Atoll National Wildlife Refuge) and the Palmyra Atoll Research Consortium (PARC). For genetic analysis, we thank Frank Hailer and Elizabeth Ann Schreiber at Smithsonian Institute. Invaluable analytical assistance was provided by D. Mucciarone. For assistance in the field we thank L. Anderegg, W. Anderegg, S. Barclay, A. Briggs, G. Carroll, P. de Salles, Z. Drozdz, C. Hanson, M. Kunz, K. Lone, J. McCallen, L. Palumbi, T. Robbins, and J. Tam. Quikscat vector wind data was provided by NASA's Jet Propulsion Laboratory Physical Oceanography Data Active Access Center, California Institute of Technology. MODIS chlorophyll a data was provided courtesy of NASA Goddard Space Flight Center, Ocean Biology Products Group. SST data was provided courtesy of Remote Sensing Systems Inc., Santa Rosa, CA.

\section{LITERATURE CITED}

Ainley DG (1977) Feeding methods in seabirds: a comparison of polar and tropical nesting communities in the eastern Pacific Ocean. In: Llano GA (ed) Adaptations within Antarctic ecosystems. Proceedings of the 3rd SCAR Symposium on Antarctic biology. Smithsonian Institution, Washington, DC, p 669-685
Anderson DJ, Ricklefs RE (1987) Radio-tracking masked and blue-footed boobies (Sula spp.) in the Galapagos Islands. Natl Geogr Res 3:152-163

Anderson DJ, Ricklefs RE (1992) Brood size and food provisioning in masked and blue-footed boobies (Sula spp.). Ecology 73:1363-1374

> Andersson M, Norberg RÅ (1981) Evolution of reversed sexual size dimorphism and role partitioning among predatory birds, with a size scaling of flight performance. Biol J Linn Soc 15:105-130

Ashmole NP (1971) Sea bird ecology and the marine environment. In: Farner DS, King JR (eds) Avian biology, Vol I. Academic Press, New York, p 223-286

Ashmole NP, Ashmole MJ (1967) Comparative feeding ecology of seabirds of a tropical ocean island. Bulletin 24, Peabody Museum of Natural History, Yale University, New Haven, CT

Asseid BS, Drapeau L, Crawford RJM, Dyer MB and others (2006) The food of three seabirds at Latham Island, Tanzania, with observations on foraging by masked boobies Sula dactylatra. Afr J Mar Sci 28:109-114

Au DWK, Pitman RL (1986) Seabird interactions with dolphins and tuna in the eastern tropical Pacific. Condor 88:304-317

Ballance LT, Pitman RL, Reilly SB (1997) Seabird community structure along a productivity gradient: importance of competition and energetic constraint. Ecology 78:1502-1518

Bantock TM, Prys-Jones RP, Lee PLM (2008) New and improved molecular sexing methods for museum bird specimens. Mol Ecol Resour 8:519-528

Belk MC, Smith HD, Lawson J (1988) Use and partitioning of montane habitat by small mammals. J Mammal 69:688-695

> Brewer ML, Hertel F (2007) Wing morphology and flight behavior of pelecaniform seabirds. J Morphol 268: 866-877

Catry T, Ramos JA, Jaquemet S, Faulquier L and others (2009) Comparative foraging ecology of a tropical seabird community of the Seychelles, western Indian Ocean. Mar Ecol Prog Ser 374:259-272

Chaurand T, Weimerskirch H (1994) The regular alternation of short and long trips in the blue petrel Halobaena caerulea: a previously undescribed strategy of food provisioning in a pelagic seabird. J Anim Ecol 63:275-282

Cherel Y, Le Corre M, Jaquemet S, Ménard F, Richard P, Weimerskirch H (2008) Resource partitioning within a tropical seabird community: new information from stable isotopes. Mar Ecol Prog Ser 366:281-291

> Croxall JP, Prince PA (1980) Food, feeding ecology and ecological segregation of seabirds at South Georgia. Biol J Linn Soc 14:103-131

Fairbairn J, Shine R (1993) Patterns of sexual size dimorphism in the seabirds of the Southern Hemisphere. Oikos 68: $139-145$

Fefer SI (1987) Trip report to Palmyra Atoll, 16-30 September 1987. US Fish and Wildlife Service Administrative Report, Honolulu, HI

Fefer SI, Harrison CS, Naughton MB, Shallenberger RJ (1984) Synopsis of results of recent seabird research conducted in the northwestern Hawaiian Islands. In: Grigg RW, Tanove KY (eds) Resource investigations in the northwestern Hawaiian Islands. University of Hawaii Sea Grant College Program, UNIHI-SEAGRANT-MR-84-01, Honolulu, p 9-76

Fridolfsson AK, Ellegren H (1999) A simple and universal method for molecular sexing of non-ratite birds. J Avian Biol 30:116-121

Gentemann CL, Minnett PJ, Sienkiewicz J, DeMaria M and others (2009) MISST: the Multi-sensor Improved Sea Sur- 
face Temperature project. Oceanography 22:76-87

Gilardi JD (1992) Sex-specific foraging distributions of brown boobies in the eastern tropical Pacific. Colon Waterbirds 15:148-151

González-Solís J, Croxall JP, Wood AG (2000a) Sexual dimorphism and sexual segregation in foraging strategies of northern giant petrels Macronectes halli during incubation. Oikos 90:390-398

González-Solís J, Croxall JP, Wood AG (2000b) Foraging partitioning between giant petrels Macronectes spp. and its relationship with breeding population changes at Bird Island, South Georgia. Mar Ecol Prog Ser 204:279-288

Gray CM, Hamer KC (2001) Food-provisioning behavior of male and female Manx shearwaters, Puffinus puffinus. Anim Behav 62:117-121

> Griffiths R, Double MC, Orr K, Dawson RJG (1998) A DNA test to sex most birds. Mol Ecol 7:1071-1075

Hamman IM, Boehlert GW, Wilson CD (2004) Effects of steep topography on the flow and stratification near Palmyra Atoll. Ocean Dyn 54:460-473

Harrison CS (1990) Seabirds of Hawaii: natural history and conservation. Cornell University Press, Ithaca, NY

Hertel F, Ballance LT (1999) Wing ecomorphology of seabirds from Johnston Atoll. Condor 101:539-556

> Inger R, Bearhop S (2008) Application of stable isotope analyses to avian ecology. Ibis 150:447-461

Jaquemet S, Le Corre M, Marsac F, Potier M, Weimerskirch H (2005) Foraging habitats of the seabird community of Europa Island (Mozambique Channel). Mar Biol 147:573-582

> Le Corre M, Jouventin P (1997) Kleptoparasitism in tropical seabirds: vulnerability and avoidance responses of a host species, the red-footed booby. Condor 99:162-168

Le Corre M, Cherel Y, Lagarde F, Lormée H, Jouventin P (2003) Seasonal and inter-annual variation in the feeding ecology of a tropical oceanic seabird, the red-tailed tropicbird, Phaethon rubricauda. Mar Ecol Prog Ser 255: 289-301

Lewis S, Sherrat TN, Hamer KC, Wanless S (2001) Evidence of intra-specific competition for food in a pelagic seabird. Nature 412:816-819

> Lewis S, Benvenuti S, Dall'Antonia L, Griffiths R and others (2002) Sex-specific foraging behavior in a monomorphic seabird. Proc Biol Sci 269:1687-1693

Longhurst AR, Pauly D (1987) Ecology of tropical oceans. Academic Press, San Diego, CA

> Lormée H, Barbraud C, Chastel O (2005) Reversed sexual size dimorphism and parental care in the red-footed booby Sula sula. Ibis 147:307-315

Martin TE (1996) Fitness costs of resource overlap among coexisting bird communities. Nature 380:338-340

McConnell BJ, Chambers C, Fedak MA (1992) Foraging ecology of southern elephant seals in relation to bathymetry and productivity of the Southern Ocean. Antarct Sci 4:393-398

McKane RB, Johnson LC, Shaver GR, Nadelhoffer KJ and others (2002) Resource-based niches provide a basis for plant species diversity and dominance in arctic tundra. Nature 415:68-71

Michener RH, Kaufman LS (2007) Stable isotope ratios as tracers in marine food webs: an update. In: Lajtha K, Michener RH (eds) Stable isotopes in ecology and environmental science. Blackwell Scientific, Boston, MA, p 238-282

Mori Y, Boyd IL (2004) Segregation of foraging between two sympatric penguin species: does rate maximisation make the difference? Mar Ecol Prog Ser 275:241-249

Naderi FM, Freilich MH, Long DG (1991) Spaceborne radar measurement of wind velocity over the ocean-an overview of the NSCAT scatterometer system. Proc IEEE 79:6

O'Reilly JE, Maritorena S, O'Brien MC, Siegel DA and others (2000) SeaWiFS postlaunch calibration and validation analyses, part 3. NASA Technical Memorandum 2000206892, Tech Rep Vol 1, NASA

$>$ Peck DR, Congdon BC (2006) Sex-specific chick provisioning and diving behaviour in the wedge-tailed shearwater Puffinus pacificus. J Avian Biol 37:245-251

Pennycuick CJ (1989) Bird flight performance: a practical calculation manual. Oxford University Press, Oxford

Perry KL (2001) SeaWinds on QuikSCAT Level 3 daily, gridded ocean wind vectors (JPL SeaWinds Project). Version 1.1, JPL Document D-20335, Jet Propulsion Laboratory, Pasadena, CA

Phillips RA, Bearhop S, McGill RR, Dawson DA (2009) Stable isotopes reveal individual variation in migration strategies and habitat preferences in a suite of seabirds during the nonbreeding period. Oecologia 160:795-806

Pianka ER (1981) Competition and niche theory. In: May RM (ed) Theoretical ecology, 2nd edn. Sinauer Associates, Sunderland, MA, p 167-196

Roe HJ (1974) Observations on the diurnal vertical migrations of an oceanic animal community. Mar Biol 28:99-113

Selander RK (1966) Sexual dimorphism and differential niche utilization in birds. Condor 68:113-151

Shaffer SA, Weimerskirch H, Costa DA (2001) Functional significance of sexual dimorphism in wandering albatross Diomedea exulans. Funct Ecol 15:203-210

> Spear LB, Ainley DG (1997) Flight behavior of seabirds in relation to wind speed and direction. Ibis 139:221-233

Spear LB, Ainley DG, Walker WA (2007) Foraging dynamics of seabirds in the eastern tropical Pacific Ocean. In: Studies in avian biology, No. 35. Cooper Ornithological Society, Los Angeles, CA

> Tremblay Y, Roberts AJ, Costa DP (2007) Fractal landscape method: an alternative approach to measuring area restricted searching behavior. J Exp Biol 210:935-945

> Weimerskirch H, Bartle JA, Jouventin P, Stahl JC (1986) Comparative ecology of six albatross species breeding on the Crozet Islands. Ibis 128:195-213

Weimerskirch H, Cherel Y, Cuenot-Chaillet F, Ridoux V (1997) Alternative foraging strategies and resource allocation by male and female wandering albatrosses. Ecology 78:2051-2063

Weimerskirch H, Le Corre M, Jaquemet S, Marsac F (2005) Foraging strategy of a tropical seabird, the red footed booby, in a dynamic marine environment. Mar Ecol Prog Ser 288:251-261

> Weimerskirch H, Le Corre M, Ropert-Coudert Y, Kato A, Marsac F (2006) Sex-specific foraging behavior in a seabird with reversed sexual dimorphism, the red-footed booby. Oecologia 146:681-691

> Weimerskirch H, Le Corre M, Bost CA (2008) Foraging strategy of masked boobies from the largest colony in the world: relationship to environmental conditions and fisheries. Mar Ecol Prog Ser 362:291-302

Weimerskirch H, Shaffer SA, Tremblay Y, Costa DP and others (2009a) Species- and sex-specific differences in foraging behaviour and foraging zones in blue-footed and brown boobies in the Gulf of California. Mar Ecol Prog Ser 391:267-278

Weimerskirch H, Le Corre M, Gadenne H, Pinaud D, RopertCoudert Y, Kato A, Bost CA (2009b) Relationship between reversed sexual dimorphism, breeding investment and foraging ecology in a pelagic seabird, the masked booby. Oecologia 161:637-649 